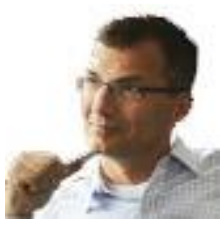

\title{
Do translation standards encourage effective terminology management?
}

\author{
Uwe Muegge \\ Director of Solutions Architecture \\ Z-Axis Tech Solutions
}

\section{ABSTRACT}

This article explores the guidance three recently published international translation standards provide in the area of translation-oriented terminology management. The author identifies perceived gaps in these standards and offers suggestions for bridging them..

Keywords: ASTM F2575, ISO 11669, ISO 17100, terminology, terminology management, translation standards, translation business, translation management

RESUM (Els estàndards de traducció fomenten una gestió terminològica eficaç?)

Aquest article explora les directrius que proporcionen tres estàndards de traducció internacionals publicats recentment en l'àmbit de la gestió terminològica orientada a la traducció. L'autor identifica les llacunes que es poden observar en aquests estàndards i suggereix com superar-les.

Paraules clau: ASTM F2575, ISO 11669, ISO 17100, terminologia, gestió terminològica, estàndards de traducció, sector empresarial de traducció, gestió de traducció

RESUMEN (¿Los estándares de traducción fomentan una gestión terminológica eficaz?)

Este artículo explora las directrices que proporcionan tres estándares de traducción internacionales publicados recientemente en el ámbito de la gestión terminológica orientada a la traducción. El autor identifica las lagunas que se pueden observar en esos estándares y sugiere cómo salvarlas.

Palabras clave: ASTM F2575, ISO 11669, ISO 17100, terminología, gestión terminológica, estándares de traducción, sector empresarial de traducción, gestión de traducción

\section{Introduction}

If you want to have an awkward conversation with someone involved in the language industry, be they on the buyer or the vendor side, just ask this simple question: "How exactly do you manage terminology?" More often than not, you will get evasive maneuvers and smoke and mirrors in response. It is an open secret that many organizations do not manage terminology well, if at all.

Is that because there is no real need for terminology as far as translation is concerned? Certainly not. In fact, in one of, if not the most comprehensive global survey on terminology management, which involved more than 1500 linguists, $92 \%$ of respondents identified terminology management as a 'very important' part of the translation process. (SDL, 2010: 7) 
On the other hand, the same survey revealed that only $15 \%$ of clients actually drive terminology management during translation/localization projects (SDL, 2010: 7).

Clearly, there is a discrepancy between the stated need of translation service providers for terminology and the ability or willingness of buyers/requestors of translation services to provide/pay for the development of multilingual terminology.

\section{The story translation standards tell}

\subsection{Three recent releases}

In my discussion of how terminology management is covered in current translation standards, I will be focusing on three recently released international standards, i.e. ASTM F2575-2014 published by ASTM International, and two translation standards published by the International Organization for Standardization, namely ISO 11669-2012 and ISO 17100-2015.

\subsection{ASTM F2575-2014 Standard Guide for Quality Assurance in Translation}

\subsubsection{What F2575-2014 says about terminology management}

The initial version of ASTM F2575 was released in 2006, and an updated version of this standard was published in 2014. One of the reasons I have been very fond of ASTM F2575 is that this standard provides a comprehensive list of parameters, or factors that need to be specified at the beginning of a translation project. These parameters, developed by Alan Melby, (Melby, 2007) are organized in four categories (i.e. linguistic, production tasks, environment, and readership). It is the 21 translation parameters, and the detailed description of competencies for selecting a translation service provider (e.g. source and target language competence, translation competence, translation technology competence), that have led me to use F2575 in the classroom almost immediately after its first release.

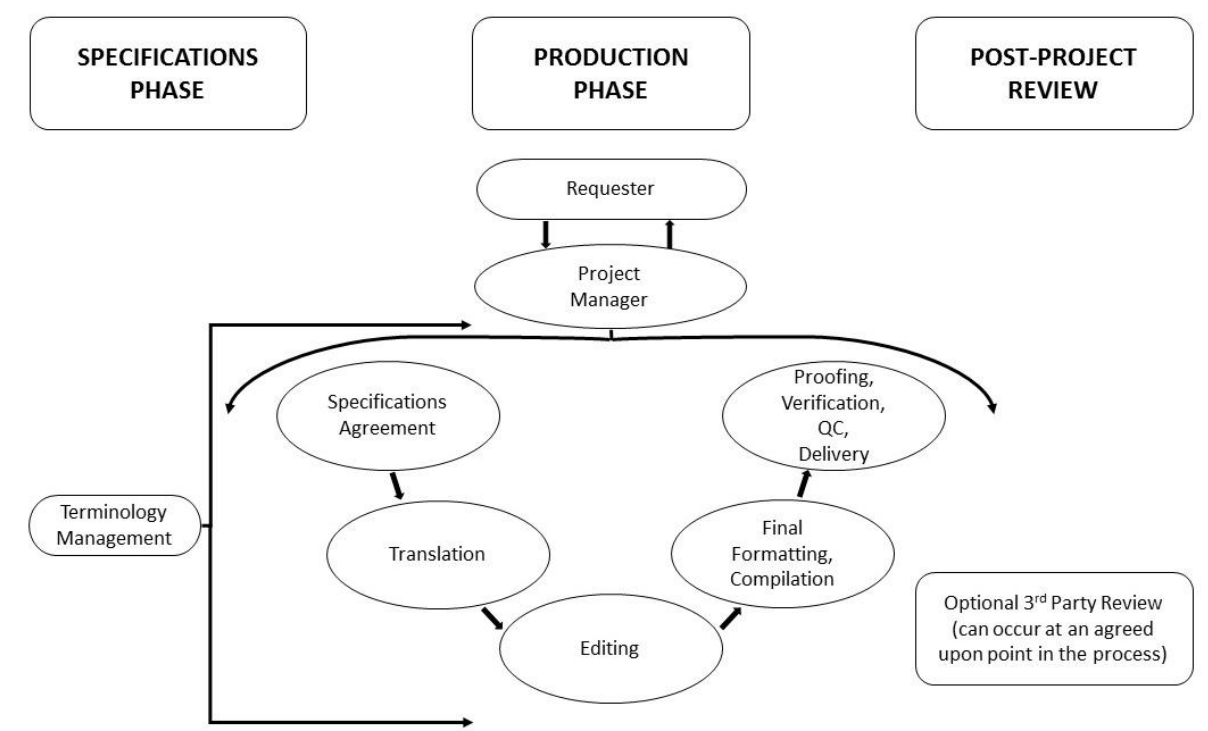

Figure 1: Diagram of the project phases as outlined in ASTM F2575 
As terminology is one of the 21 translation parameters, which arguably constitute the core of F2575-2014, it is not surprising that terminology work is addressed in multiple parts of the document.

In the description of the project phases, the standard explains that to "ensure a high degree of quality from a process point of view, all steps shown inside the ovals in Fig. 1 must be followed", and clearly, terminology management is not one of those steps. This section also states that terminology management "should apply throughout the entire project to ensure terminological consistency" (ASTM, 2014: 7).

The section on the specifications phase recommends that "unusual terms, or terms that must be translated in a particular way for this project, should be included in a bilingual terminology database (term-base) that is supplied by the requester or developed by the provider" and continues that "if the provider is expected to develop terminology resources, this expectation must be made explicit in Additional Tasks" (ASTM, 2014: 8).

The most comprehensive discussion of terminology management in F2575-2014 can be found in the part covering the production phase, which includes an entire section on terminology management. In this section, the standard recommends again that requestors share with the translation service provider any terminology resources they may have, and that they do so at the beginning of a project. The standard goes on to stipulate that if "such resources do not exist, the translation service provider will create a glossary, at a minimum, to ensure consistency and accuracy of terminology used throughout the translation" (ASTM, 2014: 10).

\subsubsection{My interpretation of the terminology management component of F2575-2014}

F2575 is a guideline standard, which means that this entire document is designed 'for information only'. As such, this standard does not and cannot include a requirement to perform comprehensive terminology work as part of a translation project. But while F25752014 is very clear in recommending certain steps that "must be followed" in the translation process, the language for recommending terminology management is much less stringent: It only "should apply" at the various phases of a translation project (ASTM, 2014: 7). Also, while F2575-2014 states that the translation service provider "will create a glossary" if the requestor does not provide one, the standard does not at all specify that such a glossary be comprehensive (ASTM, 2014: 10). In fact, it could be argued that the fact that translation buyers must specifically request this type of work as an 'additional task' indicates the optional nature of terminology management as part of translation projects (ASTM, 2014: 8).

And what justification for doing translation-oriented terminology work does ASTM F2575 offer? This being a translation quality standard, it is not surprising that F2575-2014 only mentions two reasons for managing terminology during a translation project, namely to "ensure consistency and accuracy of terminology" (ASTM, 2014: 10). 


\subsection{ISO 11669-2012 Translation projects - General guidance}

\subsubsection{What ISO 11669-2012 says about terminology management}

Like ASTM F2575, ISO 11669 is a guideline standard. And the similarities don't end there: Just like F2575, ISO 11669 features the 21 translation parameters developed by Alan Melby and emphasizes the importance of structured communication between the various stakeholders in a translation project. So one way of looking at ISO 11669 is as an evolution of the original, 2006-version of the ASTM translation standard. Looking at the space devoted to terminology management, ISO 11669 is a major evolutionary step forward from both ASTM F2575-06 and F2575-14. And not only in terms of quantity, but also the quality of the recommendations regarding terminology management in ISO 11669 go far beyond the ASTM translation standard.

It is curious that ISO 11669 first mentions terminology management in a process context in a section titled 'Complexity as a result of project specifications', in which "the creation of a terminology database" is listed as one of the "aspects of the project specifications [that] can greatly increase the complexity of a translation project and its management" (ISO, 2012: 10).

And, in the section that immediately follows the above statement, the standard states that terminology management "helps prevent terminology errors and inconsistencies, particularly when large project teams or large volumes of source content are involved" and goes on to explain that terminology work "is crucial to nearly all translation projects and at all stages of the translation project" (ISO, 2012: 11).

\subsubsection{My interpretation of the terminology management component of ISO 11669-2012}

One of the two annexes to ISO 11669 is devoted in its entirety to terminology work. The very first sentence of the annex reads: "Terminology work applies to all stages of a translation project" (ISO, 2012: 31). This is an odd statement: Firstly, this is a repetition of an even stronger-worded version of this statement in the normative part of the standard, i.e. in section 5.1 Terminology work (ISO, 2012: 11). Secondly, the standard cites 'ISO 704-2009 Terminology Work - Principles and methods' as source of this statement. However, ISO 704 does not discuss the translation process at all. And thirdly, this sentence, in my opinion, does fall short of strongly recommending, let alone requiring, terminology work at every stage of a translation project.

Instead of using the annex to provide a sample workflow or some other, more detailed description of comprehensive, translation-oriented terminology management, the annex on terminology work repeats, almost verbatim, a section from the normative part of the standard, i.e. the first two paragraphs of section 5.3.2 Preparation, which states that the translation service provider should extract terms in the source that are not included in any resources the requester provided and that this type of task "can be vitally important to the translation project and should not be neglected" (ISO, 2012: 13, 31). 
So yes, this guideline standard does support the idea of doing translation-oriented terminology work. But the only specific reasons for managing terminology that I could find in ISO 11669 are the same that ASTM F2575 provided, namely "to prevent terminology errors and inconsistency" (ISO, 2012: 11).

\subsection{ISO 17100-2015 Translation service - requirements for translation services}

\subsubsection{What ISO 17100 says about terminology management}

As ISO 11669 has its roots in ASTM F2575-06, so is ISO 17100 a direct descendant of EN 15038. ISO 17100 was only released in May 2015, i.e. so recently that many in the translation industry may not even be aware that a) it exists and b) it actually supersedes EN 15038 .

Unlike the two other translation standards covered in this article, ISO 17100 is not a guideline but a requirements standard, which means that a translation service provider can get - and some already are - certified against ISO 17100. In fact, ISO 17100, being published by ISO and the successor to the popular EN 15038 standard, promises to be the most widely used translation standard ever.

The first reference to terminology management in this standard is found in a section on 'Technical and technological resources' that specifies that the translation service provider has in place, "where appropriate" an infrastructure that includes, among others, "translation technology tools, translation management systems, terminology management systems, and other systems for managing translation-related language resources" (ISO, 2015: 7).

It is remarkable that ISO 17100 is the only one among these three major translation standards that mentions terminology management systems by name.

The main section on terminology management in ISO 17100 is so brief, I can easily quote it its entirety:

The client and the translation service provider can agree that the translation service provider shall ensure that the appropriate terminology is available for the performance of the translation project. The agreement can include the scope of terminology work and descriptions of the terminology tasks to be carried out by the translation service provider and a specification that this terminology should be used. (ISO, 2015: 9)

\subsubsection{My interpretation of the terminology management component of ISO 17100-2015}

It deserves mentioning in this context that in this, as other ISO standards, the terms 'can', 'shall', and 'should' each have a very specific meaning:

- shall: used to indicate requirements strictly to be followed in order to conform to the document and from which no deviation is permitted; 
- $\quad$ should - used to indicate that, among several possibilities, one is recommended as particularly suitable, without mentioning or excluding others, or that a certain course of action is preferred but not necessarily required;

- can - used for statements of possibility and capability, whether material, physical, or causal.(ISO, 2015: iv)

In light of these definitions, the specifications in 'Terminology' in ISO 17100 indicate the possibility, not a requirement, that a translation service provider does systematic terminology work, i.e. the standard only recommends, not requires, that any terminology they create be used.

But in the section on translation, the standard lists seven specifications that the translator 'shall' comply with throughout the translation process, and the first of these specifications is: "compliance with specific domain and client terminology and/or any other reference material provided and ensuring terminological consistency during translation [...]" (ISO, 2015: 10).

By only mentioning 'terminological consistency' as motivator for terminology work, ISO 17100 , like the other two translation standards, only looks at terminology management in the context of quality assurance.

\section{The missing pieces}

\subsection{Explaining all the benefits of terminology management}

All three translation standards discussed in this article emphasize the fact that managing terminology helps avoid terminology errors in general and terminology consistency issues in particular. In other words: The standards highlight the fact that managing terminology during a translation project helps translation service providers deliver a high-quality translation product. And I whole-heartedly subscribe to this view.

But focusing exclusively on the quality-related benefits of terminology work, as all three translation standards do, does not do justice to terminology management. As I have explained in detail elsewhere, (Muegge, 2000, 2007, 2015) if a translation service provider manages terminology properly, i.e. makes a comprehensive, project-specific multilingual terminology database available to the translator and editor/reviewer at the beginning of their task, the linguists will not only use the desired terms consistently, they will also translate, edit, and review substantially faster.

ISO 11669 states that the creation of a terminology database "can greatly increase the complexity of a translation project and its management" (ISO, 2012: 10). I would contend that, if done properly, creating and using a termbase can greatly simplify a translation project - and even lead to cost reduction.

Think of a large project involving multiple translators per language. In a typical scenario, the translators would work without a project-specific termbase. And because in this kind of environment terminological inconsistencies are inevitable, an additional editing step is required just to harmonize terminology. But what if all translators had access to a 
comprehensive termbase at the beginning of a project (and use a style guide and shared translation memory)? In all likelihood, there would be no need for extensive harmonization of terms. In other words: Translators would do it right the first time, eliminating the need to correct (terminological) quality into a translation.

\subsection{Explaining the translation tools ecosystem}

While all three translation standards state, more or less forcefully, that it is a good idea to use terminology/terminology databases/termbases throughout a translation project, not a single one of these standards goes into any detail as to what type of tools should be used to achieve this goal.

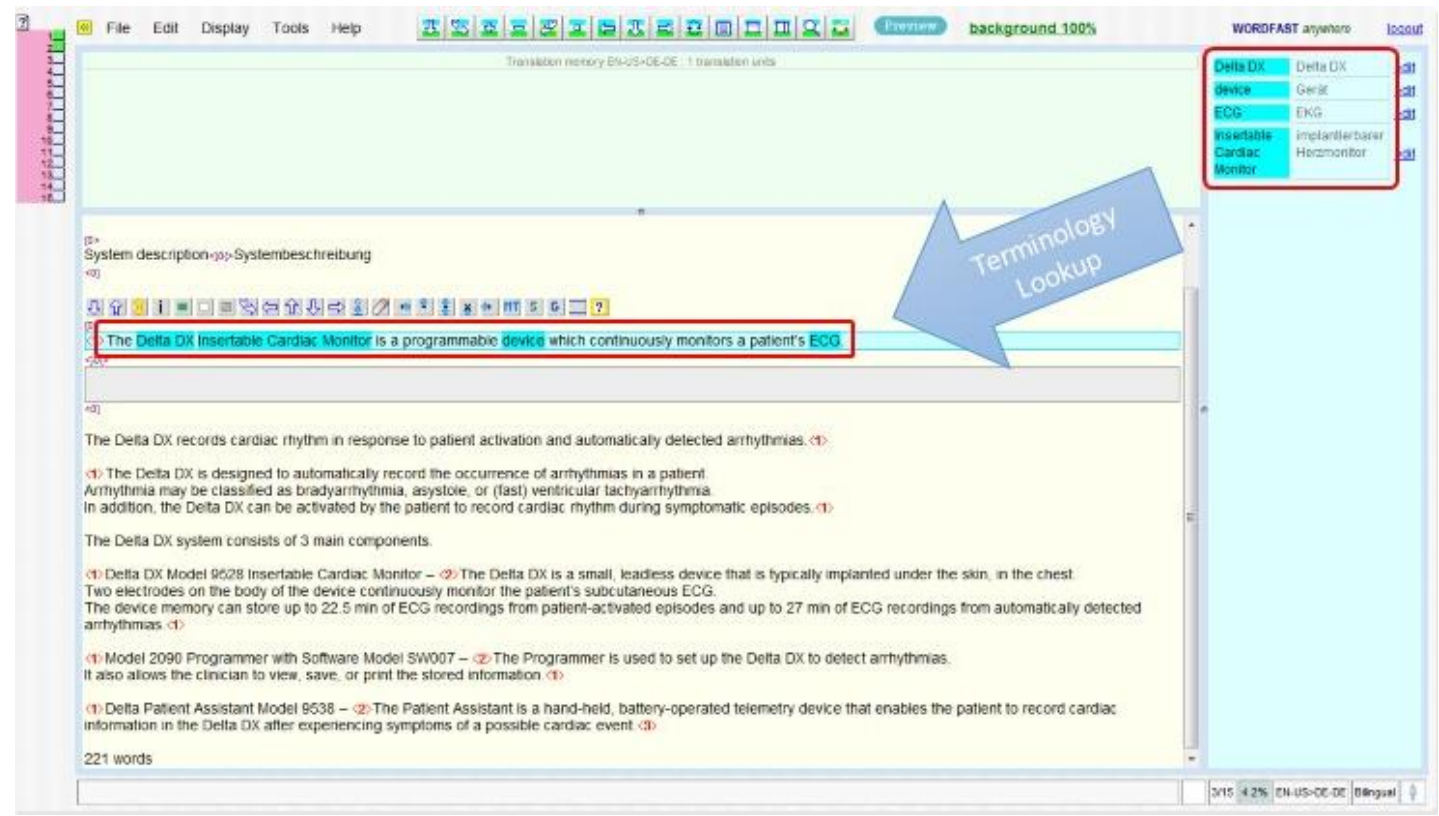

Figure 2: Automatic terminology lookup in a translation memory system

The best practice for managing terminology in human translation projects is to use a translation memory system with an integrated terminology management module. In this type of environment, the system not only recognizes terms automatically, but also provides translation proposals to the translator (and the editor/reviewer). In other words: Linguists working in a translation memory system with terminology management capabilities select terminology on the fly while translating/editing/reviewing, which is a much more efficient way of working with terminology than using external spreadsheets and inserting terms manually into a translation.

None of this is new. I have used terminology in an integrated translation memory environment more than ten years ago (Muegge, 2001), and these tools have in fact been available for more than 20 years. 


\subsection{Explaining the terminology management workflow}

Both ASTM F2575-14 and ISO 11669 contain a more or less explicit recommendations that terminology be managed at every phase of a translation project (conspicuously, there is no such language in ISO 17100) (ASTM, 2014: 7; ISO, 2012, 11). Unfortunately, nowhere in these three translation standards are there any recommendations what a sample terminology management process for a translation project could look like, and what the tasks involved in each phase would be.

Again, integrated, tools-driven, end-to-end terminology management is not a revolutionary new concept: In fact, I presented a working system composed of only slightly modified off-theshelf products back in 1999 at the TQ2000 Translation Quality conference in Leipzig (Muegge, 2007). Today, it is not only easier to create such a system, but more than 15 years later, more powerful products are available, covering many more languages than the tools I originally described.

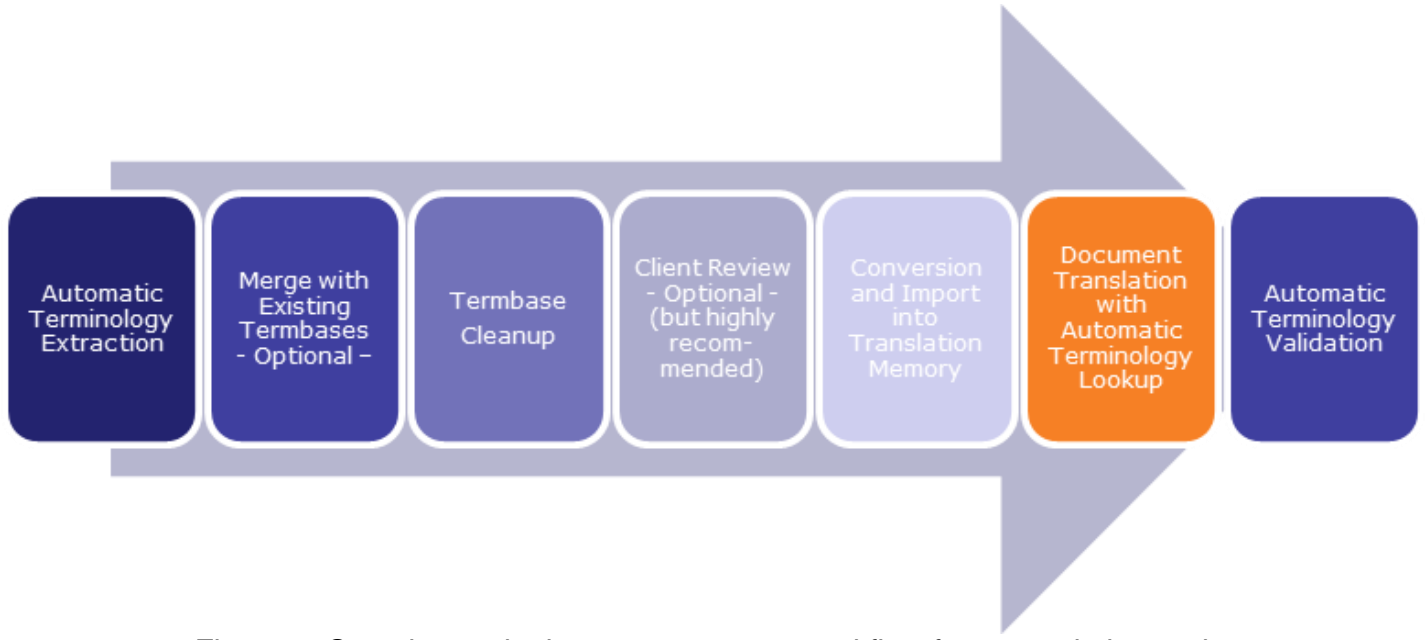

Figure 3: Sample terminology management workflow for a translation project

\section{Conclusion}

The answer to the question, "do ASTM F-2575-2014, ISO 11669-2012 and ISO 171002015 encourage terminology management?" is a clear and resounding "yes". Each of the three translation standards mentions terminology management in multiple sections, and all point out the importance of doing terminology work as part of a translation project.

But do these translation standards encourage 'effective' terminology management? I think not: None of the standards provides any guidance on how to approach terminology management from a process point of view, nor do the standards talk in any detail about the kinds of tools to use in such an effort.

Even more problematic than not discussing how to do comprehensive, translation-oriented terminology work is the fact that the standards don't provide a more compelling answer than they do to the question, "why manage terminology ?" 
I do hope that the next version of each of these translation standards, in terms of guidance on terminology management, are less a reflection of the status quo and more of the state of the art.

\section{Bibliography}

ASTM. (2014). ASTM F2575-14 Standard Guide for Quality Assurance in Translation. Conshohocken: ASTM International.

ISO. (2012). ISO/TS 11669 Translation projects - General guidance. Geneva: International Organization for Standardization.

ISO. (2015). ISO 17100 Translation services - Requirements for translation services. Geneva: International Organization for Standardization.

Melby, A. K. (2007). Translation Parameters. Provo: BYU Translation Research Group.

Muegge, U. (2000). Terminology work: Tools and processes that make a difference. The ATA Chronicle, 15-20.

Muegge, U. (2001). Translation Memory - das Werkzeug der Wahl für (fast) jedes Übersetzungsprojekt. In E. Gräfe, Proceedings of the annual conference of the German society of technical communicators (pp. 248-251). Stuttgart: tekom.

Muegge, U. (2007). Automatische Terminologieextraktion. In P. Schmitt, \& H. Jüngst, Translationsqualität (pp. 712-726). Frankfurt: Peter Lang.

Muegge, U. (2007). Disciplining words: What you always wanted to know about terminology management. tcworld, 17-19.

Muegge, U. (2015). Product-centric translation: What it is and how best to handle it. The ATA Chronicle, 14-18.

SDL. (2010). Teminology Survey. Maidenhead, UK: SDL plc. 